\title{
Expression of Apocrine Differentiation Markers in Neuroendocrine Breast Carcinomas of Aged Women
}

\author{
Anna Sapino, M.D., Luisella Righi, M.D., Paola Cassoni, M.D., Mauro Papotti, M.D., \\ Patrizia Gugliotta, Bsc, Gianni Bussolati, M.D., Frc Path \\ Department of Biomedical Sciences and Human Oncology, University of Torino, Torino, Italy
}

\begin{abstract}
Neuroendocrine (NE) breast carcinomas are a rare entity in young women; however, their frequency increases in aged patients. The present work demfollow-up of these patients, as demonstrated in two cases of the present series, can justify the immunophenotyping of the tumors.
\end{abstract} onstrates that $\mathrm{NE}$ breast carcinomas in elderly women can also express an apocrine immunophenotype and analyzes the histological and clinical aspects of such differentiation. A selected series of $50 \mathrm{NE}$ tumors (positive for NE markers in $\geq 50 \%$ of the cells) was tested for the immunocytochemical expression of gross cystic disease fluid protein-15 (GCDFP-15). The results demonstrated that about $50 \%$ of moderately (G2) and well-differentiated (G1) NE breast carcinomas (mucinous, solid papillary, and solid cohesive histotypes) coexpressed the apocrine marker. In these cases, specific mRNA for GCDFP-15 (PIP) and for chromogranin A (ChA) was demonstrated using in situ hybridization (ISH). Carcinomas of the alveolar subtype (G2) and poorly differentiated carcinomas (G3), including one case of atypical carcinoid, were pure NE carcinomas, devoid of apocrine differentiation. The steroid receptor status of these lesions was evaluated to test a possible involvement of androgen receptors in apocrine differentiation. We demonstrated that the level of AR and the mean age of patients at diagnosis were significantly higher in apocrine than in nonapocrine differentiated tumors. The histological grade and the expression of estrogen receptor (ER) significantly influenced the prognosis of these $\mathrm{NE}$ carcinomas, either pure or NE-apocrine differentiated. The most original result of our study is therefore the demonstration of a possible divergent apocrine differentiation of $\mathrm{NE}$ breast carcinomas that might be regulated by the activation of androgen receptors in elder patients. In addition, the possibil-

Copyright () 2001 by The United States and Canadian Academy of Pathology, Inc.

VOL. 14, NO. 8, P. 768, 2001 Printed in the U.S.A.

Date of acceptance: March 19, 2001.

This work was supported by grants from the M.U.R.S.T. (Ministero della Ricerca Scientifica e Tecnologica; Rome) and Piedmont Region (D.G.R. 23-26314 Grant 00039).

Address reprint requests to: Anna Sapino, M.D., Department of Biomedical Sciences and Human Oncology, University of Turin, Via Santena, 7, 10126 Torino, Italy; e-mail: anna.sapino@unito.it; fax: 0039-011-663-5267.

ity for using Chs or GCDFP-15 serum values in the

KEY WORDS: Age, Apocrine, Breast carcinoma, Hormone receptor, Neuroendocrine.

Mod Pathol 2001;14(8):768-776

Carcinomas of the breast are a multifaceted entity that may show various types of differentiation. In breast carcinomas of usual type, focal neuroendocrine (NE) and apocrine differentiation is occasionally detected in scattered cells by the immunocytochemical expression of $\mathrm{NE}$ and apocrine markers (1-4). In addition, Nesland et al. (5) described scattered hormone-producing cells in two cases of apocrine carcinoma. Expression of chromogranin-A (ChA) has also been demonstrated in 3 to $5 \%$ of cells of a particular variant of invasive lobular carcinoma, the so-called histiocytoid carcinoma, which is diffusely immunoreactive for the apocrine protein GCDFP-15 $(6,7)$.

Apocrine differentiation in breast carcinomas is consistently linked to overexpression of androgen receptors (AR; 8) and, on the other hand, a series of "carcinoid" of the breast was shown to express AR in $>50 \%$ of cases (9).

Taken together, these data suggest a link between $\mathrm{NE}$ and apocrine differentiation in breast carcinomas. To test this hypothesis, we investigated the possible production of the apocrine marker GCDFP-15 by NE-differentiated breast carcinomas. In addition, we analyzed the expression of steroid receptors and, in particular, of $\mathrm{AR}$, as mediators of NE-apocrine differentiation.

In other nonendocrine organs, pure NE tumors are considered lesions homogeneously positive for NE markers $(10,11)$ and correlated to a specific clinical evolution. As a consequence, we recently defined as pure NE-differentiated breast carcinomas those tumors having a relevant percentage $(\geq 50 \%)$ of cells expressing NE markers $(2,12)$. In the present study, we followed the same immunohistochemical approach to define tumors as pure 
NE or as NE-apocrine differentiated, and we evaluated whether the different immunophenotype could be related to specific clinical features.

\section{MATERIALS AND METHODS}

\section{Case Series}

A series of $50 \mathrm{NE}$ breast carcinomas that expressed at least one NE marker (namely chromogranin A $[\mathrm{ChA}]$, chromogranin B $[\mathrm{ChB}]$, or synaptophysin [Syn]) in $\geq 50 \%$ of their cells was studied for the presence of the apocrine marker GCDFP-15. Forty-five tumors were part of a previously reported series of NE breast carcinomas (2). Five other cases, fitting the above reported immunocytochemical features, were obtained from a series of 153 breast carcinomas collected over a 9-month period in our department. The whole series of $50 \mathrm{NE}$ carcinomas was subdivided according to our proposed classification (2) and the Elston and Ellis histological grading system (13).

The correlation of immunophenotype (pure NE or NE-apocrine) with the expression of the different NE markers (ChA, ChB, Syn) and with the hormonal receptor types was analyzed by Yates corrected $\chi^{2}$.

Age was obtained from all patients and follow-up, from 35 patients. Correlation of these clinical data with the immunophenotype, the histological grade, and the steroid receptor expression was analyzed by one-way ANOVA. Univariate analysis was based on Kaplan-Meier product-limit estimate of survival distribution using the Wilcoxon test. All data were analyzed by using a selected computer program for statistics.

\section{Immunohistochemistry}

Cases were either formalin fixed or Bouin fixed and were paraffin embedded. Parallel sections of each tumor were immunostained using the antibodies listed in Table 1. Immunohistochemical analysis of steroid receptors was possible on formalin fixed tissues only; thus, in 13 Bouin's-fixed cases, the results of the biochemical estrogen re-

TABLE 1. Panel of Antibodies Applied

\begin{tabular}{|c|c|c|c|}
\hline Marker & Reagent & Source & Dilution \\
\hline Chromogranin A & $\begin{array}{l}\text { LK2H10 } \\
\text { mAb }\end{array}$ & $\begin{array}{l}\text { BioGenex, San Ramon, } \\
\text { CA }\end{array}$ & $1: 100$ \\
\hline Chromogranin B & $\begin{array}{l}\text { PE-11 } \\
\text { Polyclonal }\end{array}$ & $\begin{array}{l}\text { Dr R. Fischer-Colbrie, } \\
\text { Innsbruck, Austria }\end{array}$ & $1: 1000$ \\
\hline Synapthophysin & Polyclonal & $\begin{array}{l}\text { Biomeda, Foster City, } \\
\text { CA }\end{array}$ & $1: 50$ \\
\hline GCDFP-15 & Polyclonal & $\begin{array}{l}\text { Dr D. Haagensen, } \\
\text { Boston, MA }\end{array}$ & $1: 10000$ \\
\hline Androgen receptor & $\begin{array}{l}\text { F39.41 } \\
\text { mAb }\end{array}$ & BioGenex & Prediluted \\
\hline Estrogen receptor & $\begin{array}{l}1 \mathrm{D} 5 \\
\mathrm{mAb}\end{array}$ & $\begin{array}{l}\text { Zymed, San Francisco, } \\
\text { CA }\end{array}$ & $1: 50$ \\
\hline Progesterone receptor & $\begin{array}{l}\text { PgR-ICA } \\
\text { mAb }\end{array}$ & $\begin{array}{l}\text { Dakopatts, } \\
\text { Copenhagen, Denmark }\end{array}$ & $1: 5$ \\
\hline
\end{tabular}

ceptor (ER) and progesterone receptor (PR) assay were used (cutoff value for positive cases was $>20$ $\mathrm{fmol} / \mathrm{mg}$ ).

Endogenous peroxidase activity was inhibited with $6 \% \mathrm{H}_{2} \mathrm{O} 2$ for 5 minutes before the incubation with the primary antibodies. When antigen retrieval was necessary, the sections were incubated with specific avidin- and biotin-blocking reagents (avidin/biotin blocking kit, Biogenex, San Ramon, CA), as described elsewhere (14). Heat-induced antigen retrieval was performed by pretreating the sections in a microwave oven (three 3-minute passages at $750 \mathrm{~W}$ in $1 \mathrm{~mm}$ EDTA buffer, $\mathrm{pH} 8.0$, or in $10 \mathrm{~mm}$ citrate buffer, $\mathrm{pH}$ 6.0). In selected cases, the immunoreactivity for ChA was enhanced using biotinyl-tyramide to increase the sensitivity of the detection system.

In all cases, the sections were then washed in phosphate buffered saline and the reaction was revealed using the LSAB2 kit peroxidase streptavidin universal system (DAKO, Glostrüp, Denmark) for 30 minutes and developed in a solution containing $15 \mathrm{mg} / 100 \mathrm{~mL}$ phosphate buffered saline of 3,3'-diaminobenzidine (3,3'-diaminobenzidine) and $0.3 \% \mathrm{H}_{2} \mathrm{O}_{2}$. Nuclei were counterstained using hemalum.

To evaluate the coexpression of $\mathrm{ChA}$ and GCDFP-15 in selected cases, a two-step double immunostaining was performed. In the first step, ChA was revealed with 3,3'-diaminobenzidine, whereas the second step involved the detection of GCDFP-15 immunoreactivity by $\beta$-galactosidase-conjugated secondary antibody. The reaction was developed with 5 'bromo-4chloro-3 indoxyl $\beta$-galactosidase (15). Sections were then mounted in Canada balsam.

\section{In Situ Hybridization}

In 21 cases positive for GCDFP-15, ISH for GCDFP-15 mRNA (PIP) and for ChA mRNA was performed as described elsewhere (4-16).

A 600-base pair cDNA encoding human PIP cloned into the pVZI bluescript plasmid vector (pPIP-8-3-cDNA clone, kindly supplied by Dr. R. Shiu and Y. Myal, Winnipeg, Manitoba, Canada) was used for ISH. The probe was cleaved with the restriction enzyme XbaI. Antisense RNA molecules were obtained using a T7 RNA polymerase and digoxigenin RNA-labeled nucleotide mixture containing DIG-11dUTP (DIG RNA labeling kit, Boehringer, Mannheim, Germany).

Briefly, after proteinase $\mathrm{K}$ digestion, the slides were treated with the hybridization mixture containing the antisense digoxigenin-labeled RNA probe. After incubation, the nonspecifically bound single-strand RNA probe was removed by RNAse digestion. The specifically bound hybridized probe was revealed using anti-digoxigenin antibodies conjugated with alkaline phosphatase. Color was developed using a nitroblue tetrazolium salt sub- 
strate. Nuclei were counterstained with methyl green. Slides were then dehydrated and mounted.

For ChA ISH, 10 oligonucleotide probes were synthesized with an automated DNA synthesizer from published nucleotide sequences (17), and the probes were digoxigenin labeled. Briefly, the sections were treated in $10 \mathrm{mM}$ of citrate buffer, $\mathrm{pH}$ 6.0 , in a microwave oven at $800 \mathrm{~W}$ for 5 minutes, then they were incubated in proteinase $\mathrm{K}$ and, finally, in the hybridization mixture containing the oligonucleotide-labeled probes. The specifically bound hybridized probes were then revealed using peroxidase-conjugated anti-digoxigenin antibodies and developed in a 3,3'-diaminobenzidine solution. Nuclei were counterstained using hemalum.

\section{RESULTS}

\section{Histotypes of NE Breast Carcinomas}

Thirteen cases were NE mucinous carcinomas (Type B; 18, 19). The cells (plasmacytoid, spindle, or with signet ring appearance) formed cribriform or solid islands floating within the mucin lakes (Fig. 1, A-C). Mitoses ranged from 4 to 10 per 10 high power fields (HPF). Nine cases were well differentiated (G1), and four were moderately differentiated (G2) carcinomas.

Nine cases corresponded to those described by Maluf and Koerner (20) as "solid papillary carcinomas" and by Tsang and Chan (21) as "endocrine ductal carcinoma in situ" of the breast. These tumors produced expansive lesions (Fig. 1, D-F) formed by solid sheets of cells. In six cases, both invasive and in situ lesions were present. Benign intraductal papillomas were present in three cases, and a "pagetoid spread" of cells within the papillomas, as described by Tsang and Chan (21), was observed in one case. These cases presented a variable amount of extracellular mucin that ranged from small pools to large lakes, as seen in mucinous carcinomas (three cases). Mitoses ranged from 2 to 6 per $10 \mathrm{HPF}$. Six of these tumors were G1, and three were G2. One of the patients developed lung metastases with a mucinous component 3 years after diagnosis. The recurrence of the disease was suspected because of the increase in ChA serum level up to $143 \mathrm{ng} / \mathrm{mL}$ (cutoff value: 20 to $100 \mathrm{ng} /$ $\mathrm{mL}$ ) observed during patient follow-up.

Fifteen cases defined as solid-cohesive carcinoma (2) or low-grade insular carcinoma (22) showed, at variance with solid papillary carcinomas, an infiltrating appearance because of a dense collagen core surrounded by highly cellular nests, or trabeculae of cells, reminding one of carcinoid tumors (Fig. 1, G-I). To these histological patterns corresponded polygonal, or plasmacytoid, or spindle cells with eosinophilic granular cytoplasm. Mi- toses never exceeded 4 per $10 \mathrm{HPF}$. Seven of these tumors were G1, and eight were G2.

The NE alveolar carcinomas (five cases) featured round alveolarlike structures, separated by scanty dense stroma that reproduced an infiltrative growth pattern (Fig. 2, C-D), similar to the alveolar variant of lobular carcinoma (23). A homogeneous population of large clear cells, with faintly granular periodic acid-Schiff-negative cytoplasm, formed these $\mathrm{NE}$ alveolar carcinomas. Mitoses ranged from 6 to 12 (mean, 10) per $10 \mathrm{HPF}$. All cases were G2.

Eight cases were classified as poorly differentiated (G3) NE carcinomas. The small-cell variety was excluded from this group (24). Poorly differentiated NE carcinoma showed crowded clusters of cells, with moderate to abundant cytoplasm; nuclei with vesicular to finely granular chromatin; and high numbers of mitoses (ranging from 18 to 65 per $10 \mathrm{HPF}$; Fig. 2, E-F). Focal areas of necrosis were present. Within this group, one case similar to the atypical carcinoid showed whirls of spindle cells and focal necrosis (19, 10). No patients of this group were known to have nonmammary carcinomas. One patient with a poorly differentiated NE carcinomas and axillary lymph node metastases had high ChA serum level at diagnosis, which decreased to basal level after surgery.

\section{Expression of NE Markers and GCDFP-15 and Correlation with Histological Grade}

The expression of the NE markers and GCDFP-15 varied in the different histotypes (Table 2). In analogy to the quantitative approach followed to define NE differentiation, cases were considered NE-apocrine differentiated when $\geq 50 \%$ of the cells were positive for GCDFP-15.

More than $50 \%$ of mucinous (Fig. 1, B-C), solid papillary (Fig. 1, E-F), and solid-cohesive (Fig. 1, $\mathrm{H}-\mathrm{I})$ histotypes were NE-apocrine carcinomas. NE markers and GCDFP-15 could be expressed either in different cells or in the same cell, as demonstrated by double immunostaining (Fig 2, A-B).

The entire alveolar (Fig. 2D) and the poorly differentiated NE carcinomas (Fig. 2F) expressed ChA and were negative or focally positive (two of eight cases of poorly differentiated NE carcinoma) for GCDFP-15. ChA expression was, in fact, significantly correlated with the pure NE phenotype $\left(\chi^{2}=\right.$ 8.26; $P=.004)$, whereas $\mathrm{ChB}$ expression was correlated with the NE-apocrine phenotype $\left(\chi^{2}=11.52\right.$; $P=$.0007). Syn expression was not correlated with any particular phenotype.

When the two immunophenotypes were correlated with the grade of differentiation, the great majority of pure-NE carcinomas were found to be high-grade tumors (G2, 66.7\%; G3, 100\%), whereas NE-apocrine carcinomas were predominantly lowgrade tumors (G1, 68.4\%; $P=.006)$. 


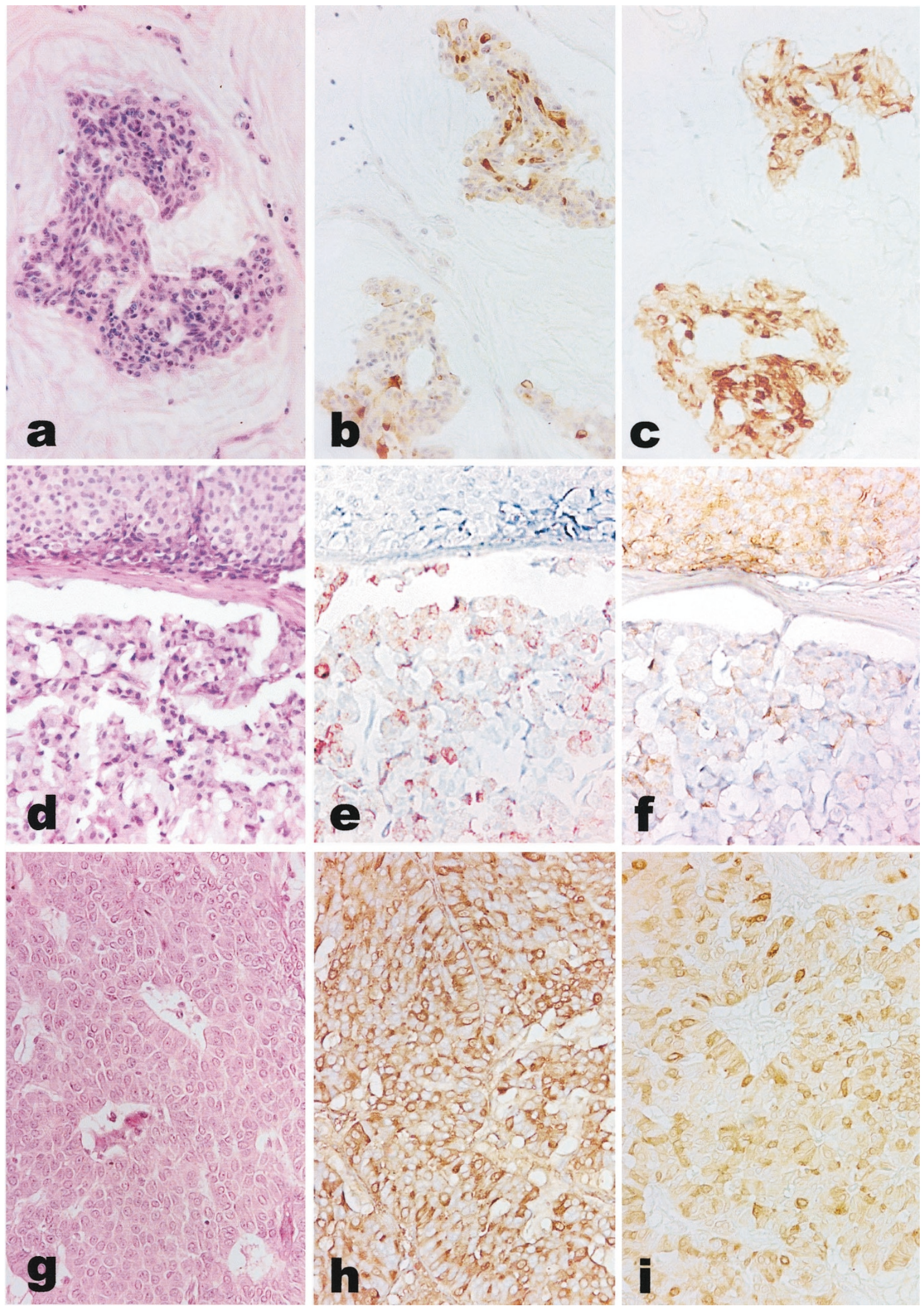

FIGURE 1. Expression of ChA and GCDFP-15 in different histotypes of NE breast cancers (mucinous, solid papillary, and solid cohesive types). A cribriform sheet of cells is floating within the mucin lakes in a mucinous NE-apocrine carcinoma (A). The same tumor is positive for ChA (B) and GCDFP-15 (C) in $>50 \%$ of cells. In a solid papillary carcinoma, a solid nest of cells (upper) is separated from a mucin-producing area by sclerotic stroma (D). ChA is expressed only in the mucinous component (E), whereas GCDFP-15 is expressed in both counterparts (F). Solid cohesive NE-apocrine carcinoma showing rosettelike structures and peripheral cell palisading are reminiscent of carcinoid tumors (G). Both ChA (H) and GCDFP-15 (I) are expressed. 
TABLE 2. Apocrine Differentiation in 50 NE Breast Carcinomas

\begin{tabular}{cccccc}
\hline $\begin{array}{c}\text { Total } \\
\text { Cases }\end{array}$ & $\begin{array}{c}\text { Morphological } \\
\text { Type }\end{array}$ & $\begin{array}{c}\mathrm{ChA}, n \\
(\%)\end{array}$ & $\begin{array}{c}\mathrm{ChB}, n \\
(\%)\end{array}$ & $\begin{array}{c}\text { Syn, } n \\
(\%)\end{array}$ & $\begin{array}{c}\text { GCDFP-15 } \\
(\%)\end{array}$ \\
\hline$\# 13$ & Mucinous & $8(61)$ & $6(46)$ & $3(23)$ & $7(54)$ \\
$\# 9$ & $\begin{array}{c}\text { Solid } \\
\text { papillary }\end{array}$ & $4(44)$ & $6(67)$ & $1(11)$ & $6(66)$ \\
$\# 15$ & $\begin{array}{c}\text { Solid } \\
\text { cohesive }\end{array}$ & $8(53)$ & $9(60)$ & $2(13)$ & $8(53)$ \\
$\# 5$ & $\begin{array}{c}\text { Alveolar } \\
\# 8\end{array}$ & $5(100)$ & neg & neg & neg \\
& $\begin{array}{c}\text { Poorly } \\
\text { differentiated }\end{array}$ & $8(100)$ & $4(50)$ & $2(25)$ & 2 foc $(0)$ \\
& & & & \\
\hline
\end{tabular}

ChA, chromogranin A; ChB, chromogranin B; Syn, synaptophysin GCDFP-15, gross cystic disease fluid protein-15; \%, percentage of positive cases in each histological type; neg, negative; foc, focal.

Specific mRNA for ChA and for GCDFP-15 was demonstrated in all cases expressing the related protein immunocytochemically (Fig. $2 \mathrm{H}$ ).

\section{Expression of Steroid Receptors}

The expression of steroid receptors on formalinfixed tissues is summarized in Table 3. AR were expressed by $80 \%$ of cells of the NE-apocrine-differentiated tumors tested (11/11 cases; Fig. 2I). In these cases, ER and PGR were expressed in about 50 to $60 \%$ of the cells. Noteworthy was the diffuse expression of AR in NE-apocrine mucinous carcinomas (4/4), whereas NE-mucinous (nonapocrine) carcinomas (three cases) were weakly positive in $<5 \%$ of cells. The pure NE carcinomas rarely expressed high nuclear levels of AR (3/13). On the contrary, ER and PGR were widely expressed.

The analysis of steroid receptor expression within the different tumor immunophenotypes revealed a significant correlation only between AR distribution and apocrine differentiation $\left(\chi^{2}=13.3 ; P=.0003\right)$.

\section{Clinical Features}

The immunophenotype of tumors was correlated with the age of patients at diagnosis. The mean age of patients with pure-NE-differentiated tumors (62.3 years) was significantly younger than that of patients with NE-apocrine tumors (72.4 years; $P<.002$ ).

Survival data were available for 35 patients. The mucinous differentiation was a favorable prognostic factor. The patients with mucinous and solid papillary carcinomas (producing some degree of mucin) had a significantly longer survival time than did patients with tumors of the other histological types $(P=.05$; Fig. 3A). In short-term follow-up, the survival was not significantly modified by the immunophenotype (pure-NE versus NE-apocrine tumors, $P=.1$ ), but 5 years after surgery, the association with apocrine differentiation improved long-term survival of patients (Fig. 3B). The histological grade was significantly correlated with prognosis. All G1 cases survived at $>13$ year follow-up, whereas the G3 NE tumors were very aggressive, and all those patients died within 6 years $(P=.007$; Fig. 3C).

The expression of ER $(P<.0001)$ was correlated with a favorable prognosis (Fig 3D), followed by PR expression $(P=.02$; Fig. 3E). AR expression did not significantly change the prognosis $(P=.19)$.

\section{DISCUSSION}

The present study demonstrates that NE and apocrine differentiation may coexist in the same breast tumor. Cells producing NE markers or GCDFP-15 in the absence of specific NE or apocrine morphology are present in the normal breast $(1,21,25)$. Similarly, in breast carcinomas, the immunocytochemical expression of apocrine markers, such as GCDFP-15, is wider than expected by morphology alone (6). As a consequence, it has been suggested that immunohistochemical techniques should be used to identify apocrine and NE differentiation in breast carcinomas, as hematoxylin and eosin identification is highly subjective and unreliable $(26,2)$.

In the present study, we considered as NE and apocrine differentiated those tumors expressing specific markers in $\geq 50 \%$ of cells. ChB expression was typically correlated with the NE-apocrine immunophenotype; on the other hand, ChA was the prevalent or the only marker produced by pure-NE carcinomas but was also present in NE-apocrinedifferentiated tumors. When the serum levels of ChA were measured in two patients affected respectively by a pure NE and an NE-apocrine tumor, they were highly above the cutoff value. This result is in agreement with the observation of high ChA serum level in small-sized $(<2 \mathrm{~cm})$ but intensely ChAimmunoreactive NE tumors (27). In addition, a potential role of GCDFP-15 as a marker of breast cancer micrometastasis has been recently proposed (28). Thus, the possibility of using Chs or GCDFP-15 serum values in the follow-up of these patients can justify the immunophenotyping of the tumors. In addition, in previous studies, the apocrine differentiation of tumors was correlated with a better prognosis $(4,29)$. In the present work, the clinical evolution was highly correlated with the histological grade, but at long-term follow-up, there was a tendency for a longer survival in patients with NEapocrine-differentiated tumors. In agreement with other studies (30), we here demonstrated that the mucin production of tumors was correlated to a better prognosis.

The steroid receptor level was also evaluated, as apocrine carcinomas consistently overexpress AR (8), and secretion of GCDFP-15 in breast carcinoma cell lines is stimulated by androgen treatment in vitro (31). Our work confirms that the AR level is higher in apocrine differentiated tumors. The apocrine tumors of our series are typical of elderly women; thus, it can 

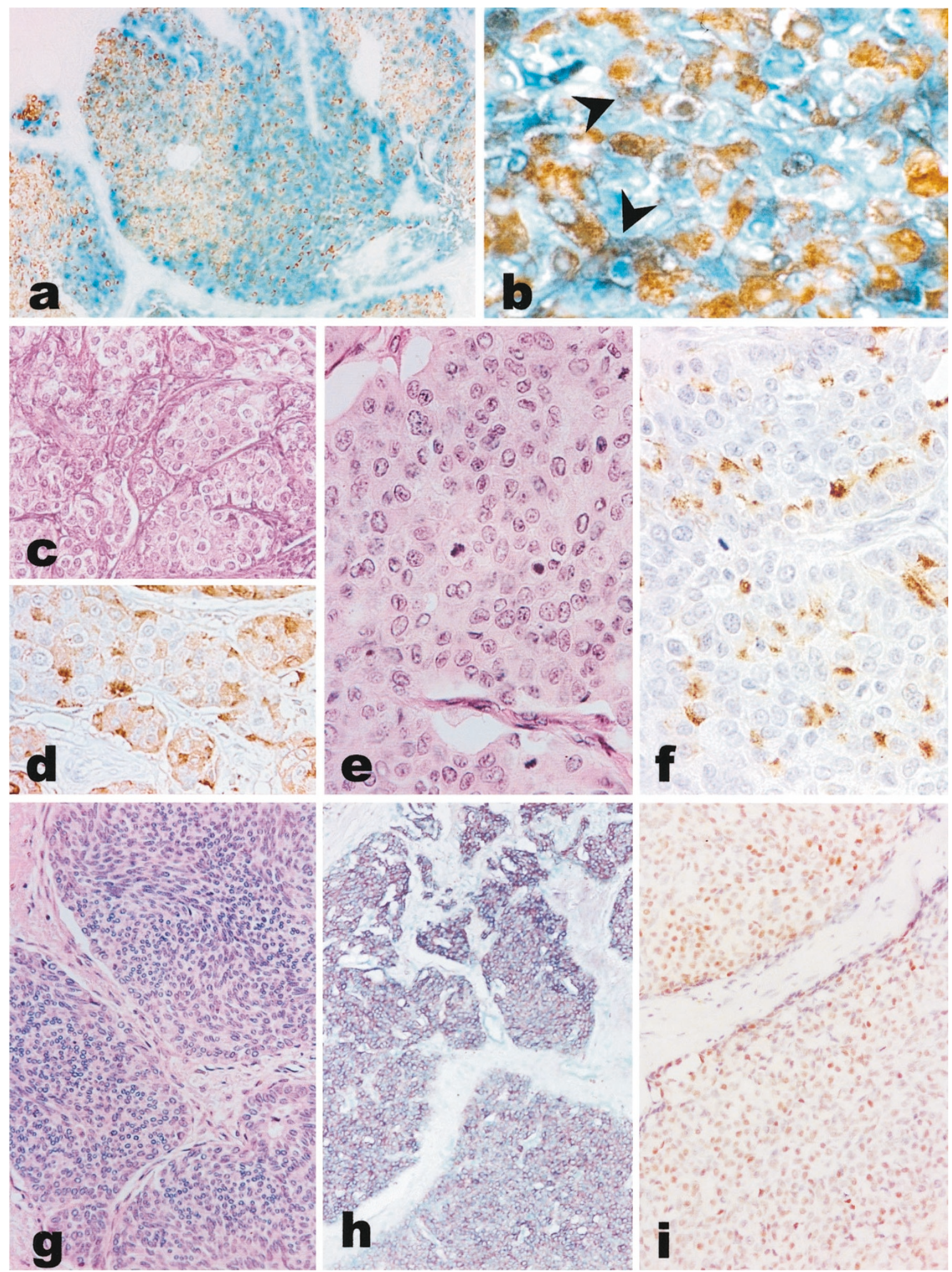

FIGURE 2. Expression of ChA, ChB, GCDFP-15, and AR in different histotypes of NE breast cancers (solid cohesive, alveolar, and poorly differentiated types). Double immunostaining of a case of solid-cohesive carcinoma (immunoperoxidase and beta-galactosidase). ChA-positive NE cells are in brown, whereas apocrine-differentiated cells expressing GCDFP-15 are in blue (A). At higher magnification, the coexpression of ChA and GCDFP-15 in the same cells (arrows) is evident (B). Pure NE alveolar carcinoma featuring round alveolarlike structures, separated by scanty dense stroma, is formed by a homogeneous population of large clear cells, with faintly granular cytoplasm (C), positive for ChA (D). Poorly differentiated NE carcinoma shows clusters of cells, with moderate to abundant cytoplasm, nuclei with vesicular to finely granular chromatin, and high number of mitoses (E). Immunostaining for ChB shows an intense cytoplasmic granular staining (F). In a case of solid-cohesive spindle cell NE-apocrine carcinoma (G), the presence of specific mRNAs for ChA GCDFP-15 (nitroblue tetrazolium salt substrate) is demonstrated with in situ hybridization (H). The nuclei of the same tumor are intensely and diffusely positive for AR (I). 
TABLE 3. Analysis of Steroid Receptors Related to Tumor Immunophenotype

\begin{tabular}{cllr}
\hline \multirow{2}{*}{$\begin{array}{c}\text { Tumor } \\
\text { Immunophenotype }\end{array}$} & \multicolumn{3}{c}{ Steroid Receptors } \\
\cline { 2 - 4 } & AR & \multicolumn{1}{c}{ ER } & PGR \\
\hline NE & $3 / 16$ & $15 / 22$ & $9 / 20$ \\
Apocrine-NE & $9 / 9$ & $15 / 16$ & $13 / 15$ \\
\hline
\end{tabular}

All data are listed as immunoreactive tumors/examined tumors. AR, androgen receptors; ER, estrogen receptors; PR, progesterone receptors.

be speculated that the relative prevalence of androgenic hormones in the menopausal period may induce the production of apocrine proteins through the activation of specific AR receptors.
Finally, this study demonstrates that the morphological features traditionally considered typical of NE breast carcinomas may be consistent also with an apocrine differentiation. Immunoelectron microscopy studies demonstrated the presence of ChA-negative dense core granules in breast carcinomas reactive for ChA in light microscopy (32), and ChA-negative dense core granules were found on the cell apex of solid papillary NE carcinomas (33). The authors presumed that these granules could be positive for other types of Chs. However, the possibility that they could correspond to those clustered towards the apex of cells in apocrine carcinomas (34) has to be considered.
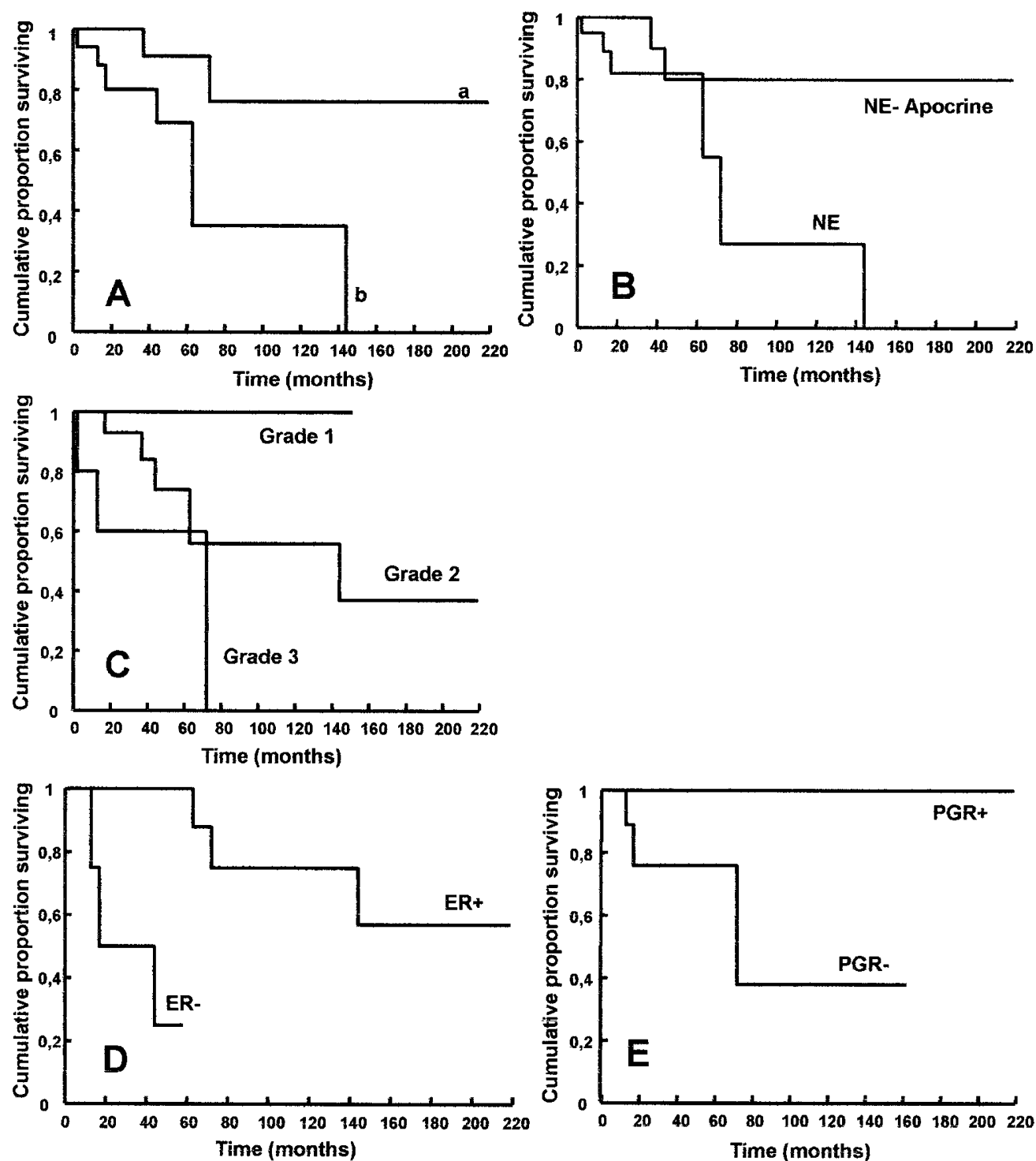

FIGURE 3. Kaplan-Meier curves of 35 patients. (A) Patients' survival is influenced by the histological type of tumors. The patients with mucinous and solid papillary carcinomas (producing some degree of mucin; a) have a significantly longer survival than patients with tumors of the other histological types $(P=.05$; b). (B) In short-term follow-up, the survival is not significantly modified by the immunophenotype (pure NE versus NEapocrine tumors, $P=.1$ ), but 5 years after surgery, there is a tendency to a better prognosis for patients with NE-apocrine tumors. (C) The histological grade influenced prognosis; in fact, patients with G1 tumors are all alive at 13 years, those with G2 tumors have an intermediate prognosis; and all patients with G3 tumors had died by the 6-year follow-up. Patients with ER- (D) and PR- (E) tumors have significantly poorer prognosis than patients with $\mathrm{ER}+$ and $\mathrm{PR}+$ tumors. 
In conclusion, the present cases may be a good example of multidirectional differentiation of breast tumors. Mixed or divergent differentiation with production of NE and exocrine protein is rather a frequent phenomenon in tumors of endocrine and nonendocrine organs $(11,35,36)$. The origin from different cell lines as colliding NE and apocrine tumors is possible. However, the immunocytochemical and in situ hybridization coexpression of NE and apocrine markers in tumors with identical morphological substrate may lead to the hypothesis of an uncommitted stem cell capable of differentiating toward both NE and apocrine lineage. Cells of welldifferentiated tumors maintain this potential, whereas those of poorly differentiated carcinomas do not show this multidifferentiation capacity and express the NE phenotype only. Our preliminary in vitro data demonstrate the presence of low levels of specific ChA mRNA in breast carcinoma cell lines producing apocrine proteins and expressing AR.

Acknowledgments: We are grateful to Mr. A. Grua for technical photographic assistance.

\section{REFERENCES}

1. Bussolati G, Gugliotta P, Sapino A, Eusebi V, Lloyd RV. Chromogranin-reactive endocrine cells in argyrophilic carcinomas ("carcinoids") and normal tissue of the breast. Am J Pathol 1985;120:186-2.

2. Sapino A, Righi L, Cassoni P, Papotti M, Pietribiasi F, Bussolati G. Expression of the neuroendocrine phenotype in carcinomas of the breast. Semin Diagn Pathol 2000;17:127-37.

3. Scopsi L, Andreola S, Pilotti S, Testori A, Baldini MT, Leoni F, et al. Argyrophilia and granin (chromogranin/secretogranin) expression in female breast carcinomas. Their relationship to survival and other disease parameters. Am J Surg Pathol 1992;16:561-76.

4. Pagani A, Sapino A, Eusebi V, Bergnolo P, Bussolati G. PIP/ GCDFP-15 gene expression and apocrine differentiation in carcinomas of the breast. Virchows Arch 1994;425:459-65.

5. Nesland JM, Memoli VA, Holm R, Gould VE, Johannessen JV. Breast carcinomas with neuroendocrine differentiation. Ultrastruct Pathol 1985;8:225-40.

6. Eusebi V, Betts C, Haagensen DE Jr, Gugliotta P, Bussolati G, Azzopardi JC. Apocrine differentiation in lobular carcinoma of the breast: a morphologic, immunologic, and ultrastructural study. Hum Pathol 1984;15:134-40.

7. Radhi JM. Immunohistochemical analysis of pleomorphic lobular carcinoma: higher expression of p53 and chromogranin and lower expression of ER and PgR. Histopathology 2000;36:156-60.

8. Gatalica Z. Immunohistochemical analysis of apocrine breast lesions. Consistent over-expression of androgen receptor accompanied by the loss of estrogen and progesterone receptors in apocrine metaplasia and apocrine carcinoma in situ. Pathol Res Pract 1997;193:753-8.

9. Birsak CA, Janssen PJ, van Vroonhoven CC, Peterse JL, van der Kwast TH. Sex steroid receptor expression in "carcinoid" tumours of the breast. Breast Cancer Res Treat 1996;40:243-9.

10. Travis WD, Colby TV, Corrin B, Shimosato Y, Brambilla E, editors. Histological typing of lung and pleural tumors. World Health Organization international histological classification of tumors. 3rd ed. New York: Springer; 1999.
11. di Sant'Agnese PA. Divergent neuroendocrine differentiation in prostatic carcinoma. Semin Diagn Pathol 2000;17:149-61.

12. Sapino A, Papotti M, Pietribiasi F, Bussolati G. Diagnostic cytological features of neuroendocrine differentiated carcinoma of the breast. Virchows Arch 1998;433:217-22.

13. Elston CW, Ellis IO. Pathological prognostic factors in breast cancer. The value of histological grade in breast cancer. I. The value of histological grade in breast cancer: experience from a large study with long-term follow-up. Histopathology 1991;19:403-10.

14. Bussolati G, Gugliotta P, Volante M, Pace M, Papotti M. Retrieved endogenous biotin: a novel marker and a potential pitfall in diagnostic immunohistochemistry. Histopathology 1997;31:400-7.

15. Bondi A, Chieregatti G, Eusebi V, Fulcheri E, Bussolati G. The use of $\beta$-galactosidase as a tracer in immunocytochemistry. Histochemistry 1982;76:153-8.

16. Pagani A, Papotti M, Abbona GC, Bussolati G. Chromogranin gene expressions in colorectal adenocarcinomas. Mod Pathol 1995;8:626-32.

17. Lloyd RV, Jin L. In situ hybridization analysis of chromogranin A and B mRNAs in neuroendocrine tumors with digoxigenin-labeled oligonucleotide probe cocktails. Diagn Mol Pathol 1995;4:143-51.

18. Capella C, Eusebi V, Mann B, Azzopardi JG. Endocrine differentiation in mucoid carcinoma of the breast. Histopathology 1980;4:613-30.

19. Papotti M, Macrì L, Finzi G, Capella C, Eusebi V, Bussolati G. Neuroendocrine differentiation in carcinomas of the breast: a study of 51 cases. Semin Diagn Pathol 1989;6:174-88.

20. Maluf HM, Koerner FC. Solid papillary carcinoma of the breast. A form of intraductal carcinoma with endocrine differentiation frequently associated with mucinous carcinoma. Am J Surg Pathol 1995;19:1237-44.

21. Tsang WYW, Chan JKC. Endocrine ductal carcinoma in situ (E-DCIS) of the breast: a form of low-grade DCIS with distinctive clinicopathologic and biologic characteristics. Am J Surg Pathol 1996;20:921-43.

22. Maluf HM, Koerner FC. Carcinomas of the breast with endocrine differentiation: a review. Virchows Arch 1994;425:449-57.

23. Fechner RE. Histologic variants of infiltrating lobular carcinoma of the breast. Hum Pathol 1975;6:373-8.

24. Shin SJ, DeLellis RA, Ying L, Rosen PP. Small cell carcinoma of the breast: a clinicopathologic and immunohistochemical study of nine patients. Am J Surg Pathol 2000;24:1231-8.

25. Viacava P, Naccarato AG, Bevilacqua G. Spectrum of GCDFP-15 expression in human fetal and adult normal tissues. Virchows Arch 1998;432:255-60.

26. Gateley CA, Bundred NJ. Apocrine breast carcinoma. Am J Clin Pathol 1991;95:903.

27. Giovanella L, La Rosa S, Ceriani L, Uccella S, Erba P, Garancini S. Chromogranin-A as a serum marker for neuroendocrine tumors: comparison with neuron-specific enolase and correlation with immunohistochemical findings. J Biol Markers 1999;14:160-6.

28. Clark JW, Snell L, Shiu RP, Orr FW, Maitre N, Vary CP, et al. The potential role for prolactin-inducible protein (PIP) as a marker of human breast cancer metastasis. Br J Cancer 1999;81:1002-8.

29. Hahnel R, Hahnel E. Expression of the PIP/GCDFP-15 gene and survival in breast cancer. Virchows Arch 1996;429:365-9.

30. Diab SM, Clark GM, Osborne CK, Libby A, Allred DC, Elledge RM. Tumor characteristics and clinical outcome of tubular and mucinous breast carcinomas. J Clin Oncol 1999;17:1442-8.

31. Hackenberg R, Schulz KD. Androgen receptor mediated growth control of breast and endometrial cancer modulated by antiandrogen- and androgen-like steroids. J Steroid Bio- 
chem Mol Biol 1996;56:113-7.

32. Battersby S, Dely CJ, Hopkinson HE, Anderson TJ. The nature of breast dense core granules: chromogranin reactivity. Histopathology 1992;20:107-4.

33. Dickersin GR, Maluf HM, Koerner FC. Solid papillary carcinoma of the breast: an ultrastructural study. Ultrastruct Pathol 1997;21:153-61.

34. Mossler JA, Barton TK, Brinkhous AD, McCarty KS, Moylan JA,
McCarty KS Jr. Apocrine differentiation in human mam-mary carcinoma. Cancer 1980;46:2463-71.

35. Capella C, La Rosa S, Uccella S, Billo P, Cornaggia M. Mixed endocrine-exocrine tumors of the gastrointestinal tract. Semin Diagn Pathol 2000;17:91-103.

36. Brambilla E, Lantuejoul S, Sturm N. Divergent differentiation in neuroendocrine lung tumors. Semin Diagn Pathol 2000;17:13848.

\section{Book Review}

\section{Hamilton SR, Aaltonen LA, editors: Pathology and Genetics of Tumours of the Digestive System 314 pp, Lyon, France, IARC Press 2000 (\$75.00).}

This is the second volume in the new WHO series on Histologic and Genetic Typing of Human Tumors. In this volume, the authors provide a review of the neoplasms of the alimentary tract including the esophagus, gastrointestinal tract, liver, biliary system, and exocrine pancreas. Each chapter is dedicated to a discussion of a specific organ and is divided into sections. The sections discuss the specific tumors of the organ or site and are authored by distinguished investigators in the respective areas. The chapters begin with the WHO histologic classification of tumors, the TMN classification, and stage grouping. Each section within the chapter begins with the WHO definition of the tumor(s), the ICD-O codes, followed by sections on the epidemiology, etiology, clinical features, including imaging (both endoscopic and radiographic), microscopy, staging, and grading. What is so beneficial in this monograph is that in each section the authors present an excellent summary of the genetics of the tumors. There are outstanding photographs throughout the textbook, demonstrating the macroscopic and microscopic features of the tumor, as well as excellent figures. The textbook, by its complete discussions of the clinical, pathologic, and genetic information, provides a unique opportunity for clinicians, pathologists, and geneticists to have a reference text (with more than 2000 citations) pertaining to alimentary system tumors suitable for all. This should be present in all departments of Medicine and Pathology/resident's libraries. In summary, this is a superb effort on the part of the editors and the contributors and is highly recommended.

Peter S. Amenta, M.D., Ph.D.

UMDNJ-Robert Wood Johnson Medical School

Piscataway, New Jersey 